\title{
No evidence for the use of stem cell therapy for tendon disorders: a systematic review
}

\author{
Haiko I M F L Pas, ${ }^{1,2}$ Maarten H Moen, ${ }^{1,3,4}$ Hidde J Haisma, ${ }^{5}$ Marinus Winters ${ }^{6}$
}

- Additional material is published online only. To view please visit the journal online (http://dx.doi.org/10.1136/ bjsports-2016-096794).

'The Sports Physician Group, Department of Sports Medicine, OLVG West, Amsterdam,

The Netherlands

${ }^{2}$ Department of Orthopaedic

Surgery, Academic Medical

Centre, Amsterdam,

The Netherlands

${ }^{3}$ Bergman Clinics, Naarden, The Netherlands

${ }^{4}$ Department of Elite Sports, NOC*NSF, Medical Staff,

Arnhem, The Netherlands ${ }^{5}$ Department of Chemical and Pharmaceutical Biology, Groningen Research Institute of Pharmacy, Groningen University, Groningen, The Netherlands

${ }^{6}$ Rehabilitation, Nursing

Science and Sports

Department, University Medical

Centre Utrecht, Utrecht,

The Netherlands

\section{Correspondence to}

Haiko IMFL Pas, Department of Orthopaedic Surgery, Academic Medical Centre, Meidreef 9, Amsterdam 1105AZ, The Netherlands; pas.haiko@gmail.com

Accepted 14 December 2016 Published Online First 11 January 2017

\section{ABSTRACT \\ Introduction Stem cells have emerged as a new treatment option for tendon disorders. We systematically reviewed the current evidence for stem cell therapy in tendon disorders.}

Methods Randomised and non-randomised controlled trials, cohort studies and case series with a minimum of 5 cases were searched in MEDLINE, CENTRAL, EMBASE, CINAHL, PEDro and SPORTDiscus. In addition, we searched grey literature databases and trial registers. Only human studies were included and no time or language restrictions were applied to our search. All references of included trials were checked for possibly eligible trials. Risk of bias assessment was performed using the Cochrane risk of bias tool for controlled trials and the Newcastle-Ottawa scale for case series. Levels of evidence were assigned according to the Oxford levels of evidence.

Results 4 published and three unpublished/pending trials were found with a total of 79 patients. No unpublished data were available. Two trials evaluated bone marrow-derived stem cells in rotator cuff repair surgery and found lower retear rates compared with historical controls or the literature. One trial used allogenic adipose-derived stem cells to treat lateral epicondylar tendinopathy. Improved Mayo Elbow Performance Index, Visual Analogue Pain scale and ultrasound findings after 1-year follow-up compared with baseline were found. Bone marrow-derived stem celltreated patellar tendinopathy showed improved International Knee Documentation Committee, Knee injury and Osteoarthritis Outcome Score subscales and Tegner scores after 5-year follow-up. One trial reported adverse events and found them to be mild (eg, swelling, effusion). All trials were at high risk of bias and only level 4 evidence was available.

Conclusions No evidence (level 4) was found for the therapeutic use of stem cells for tendon disorders. The use of stem cell therapy for tendon disorders in clinical practice is currently not advised.

\section{INTRODUCTION}

Tendon disorders, in particular tendinopathy, is a frequently seen condition in athletes and in the general population. ${ }^{1-3}$ It is defined by localised swelling, pain and functional limitations of the affected tendon. ${ }^{4}$ Several therapies, such as eccentric exercises, ${ }^{5}$ non-steroidal anti-inflammatory drugs, ${ }^{6}$ shockwave therapy, ${ }^{7-9}$ corticosteroids, ${ }^{10}$ platelet-rich plasma ${ }^{11}{ }^{12}$ and surgery ${ }^{6}$ have been used as treatments for tendinopathy, with variable levels of evidence and success. Despite some good results for some of these therapies, ${ }^{5}$ recalcitrant cases remain.
More recently, stem cells have entered the field of tendon disorder treatment. Several reviews have addressed the current evidence of cell therapy in tendinopathy and found that mostly small or large animal studies were available. ${ }^{13-18}$ Although in animal studies, there have been positive results in favour of stem cell treatment, clinical trials have been scarce and have shown only 'encouraging results'. ${ }^{13-18}$

The current model of chronic tendon disorders is based on a continuum of degeneration and failed healing ${ }^{19-21}$ with a yet unclear role of inflammatory cells. $^{20} 22-24$ This model is mainly supported by histological findings with necrotic and apoptotic tenocytes, neovascularisation and collagen disarray. ${ }^{19} 20$ Within this model, the proposed mechanism of repair through stem cell use is twofold; first through these cells' differentiating capabilities into new tenocytes they are proposed to generate new tendon tissue. ${ }^{13} 18$ Second, the paracrine effects of stem cells modulate the local immune response and stimulate repair in the surrounding cells by the production of growth factors and cytokines. $^{12} 25-28$

As more and more clinics arise that use stem cell treatments for a variety of conditions, including orthopaedic soft tissue disorders such as tendon disorders, ${ }^{29}$ and with the increasing number of trials being published on this topic, we felt it was necessary to review the current evidence. Our aim was therefore to systematically review the efficacy of stem cell therapy for pain and functional outcomes in the treatment of tendon disorders in humans.

\section{METHODS}

We systematically searched for trials that investigated the effect of stem cell therapy of any kind in tendon disorders. Randomised and nonrandomised controlled trials, cohort studies and case series with a minimum of five cases were searched. Complete selection criteria are reported in box 1 .

\section{Search methods}

With the help of a research librarian, a sensitive search strategy for multiple databases was developed by one author (MW) (see online supplementary appendix 1).

Using this strategy, one author (MW) searched all databases from the databases' inception up to June 2016. We did not impose any restrictions on our search. We searched the following electronic databases: MEDLINE-PubMed, CENTRAL, EMBASE, CINAHL, PEDro and SPORTDiscus. Furthermore, possible unpublished and ongoing trials were 


\section{Box 1 Inclusion and exclusion criteria}

Inclusion criteria

- Published and non-published human studies, randomised and non-randomised. Case series with $\geq 5$ cases.

- Patients with tendon disorders diagnosed based on history and physical examination or imaging.

- Stem cells of any origin were used as treatment, minimal proof of stem cell presence was needed (eg, automated cell analysis, surface marker analysis, culturing, etc).

- In case of controlled trials, the effect must be compared with another treatment modality, placebo or no intervention.

- Had to report at least one of the following outcomes: time to recovery (or play), recurrences, patient-reported outcomes (PROMs), pain scales, adverse events.

Exclusion criteria

- Participants with tendinopathies and other concomitant injuries which were not separately assessed.

searched in OpenGrey; the British Library Inside; Web of Science and BIOSIS Previews and several international and national trial registers: the ISRCTN registry (http://www. controlled-trials.com), the WHO trial register (apps.who.int/ trialsearch), EU clinical trial register (http://www. clinicaltrialsregister.eu); ClinicalTrials.gov and the Dutch trial register (http://www.trialregisters.nl). After inclusion of a trial, all references were hand searched for possible additional studies.

\section{Study selection}

After deletion of duplicates, two reviewers (HP and MW) independently scanned titles and abstracts of all identified studies. Full-text reports were obtained for potentially relevant studies. Both reviewers then independently applied the selection criteria (see box 1). In case of disagreement between reviewers, consensus was sought, and in case of persistent disagreement, a third party (MHM) was consulted.

\section{Data extraction}

Using a standardised data extraction sheet, two authors (HP and MW) independently extracted the following data: study design, study setting, inclusion/exclusion, details of the intervention (such as origin of stem cells used, cell isolation and culturing, dosage, frequency of administration, etc), primary and secondary outcome measures and adverse effects.

In case of disagreement, consensus was reached in a joint session. If no consensus could be reached, a third reviewer (MHM) was consulted.

\section{Risk of bias assessment}

Two reviewers (HP and MW) separately appraised the included studies for their quality. For randomised and non-randomised controlled trials, we used Cochrane Risk of Bias tool. ${ }^{30}$ We appraised each study for the five major domains of bias: selection bias (random allocation and allocation concealment), performance bias (blinding of personnel and blinding of participants), detection bias (blinding of outcome assessment), attrition bias (follow-up adequacy), reporting bias (complete outcome reporting) and other biases. We adopted previously used criteria, formulated by Winters et al, ${ }^{31}$ to score each domain (see online supplementary appendix 2). Each item was scored as to be at low (+), high (-) or unclear (?) risk of bias. Studies were considered to be at low risk of bias when all domains were scored as low $(+)$ risk of bias, or one item was at high (-) or unclear risk of bias (?). If two domains were scored as high (-) or unclear (?) risk of bias, the study was considered at moderate risk of bias. Finally, when more than two domains were scored as high (-) or unclear (?) risk of bias, the study was regarded as being at high risk of bias.

For case series, we used a modified version of the Newcastle-Ottawa quality assessment scale for cohort studies ${ }^{32}$ (see online supplementary appendix 3). A maximum of six stars could be achieved. No quality subdivision (ie, high, moderate, low risk of bias) was made for case series as these types of study are a priori at high risk of bias and a quality subdivision would not affect its level of evidence.

\section{Data synthesis}

We planned a data synthesis for randomised controlled trials (RCTs) (>2), when they were at low risk of bias and were clinically homogenous (ie, identical stem cell type and tendon disorder, cointerventions, mode of injection/transplantation). The mean difference was used for studies that used the same outcome measurement. Standardised mean differences were used for studies that used different outcome measures to estimate treatment effects. A p value $<0.05$ was considered significant for all analyses. We used a fixed effects model to pool data that were statistically homogenous, or when $<5$ studies were available for data synthesis. A random effects model was used when statistical heterogeneity was present (heterogeneity was considered present when the $\mathrm{X} 2$-test was significant, $\mathrm{p}<0.1$ ), and when $>5$ studies were available for data synthesis. We visually inspected the forest plots and the heterogeneity statistic $\left(\mathrm{I}^{2}\right)$. If heterogeneity was present, and sufficient studies were available $(\mathrm{N} \geq 10)$, we planned a subgroup analysis or meta-regression analysis to explore the sources for heterogeneity.

If data pooling was not possible, we presented our findings by means of a descriptive synthesis using the levels of evidence approach based on the Oxford Centre for Evidencebased Medicine ${ }^{33}$ (table 1). Systematic reviews were considered level 1 evidence, RCTs at low/moderate risk of bias or observational studies with a dramatic effect were considered level 2 of evidence, non-randomised controlled trials at low risk of bias at level 3 of evidence. Case series were considered as level 4 of evidence impact. Level 5 evidence was considered only when no studies were available and only mechanismbased reasoning was available. Studies were downgraded when they were at high risk of bias with the lowest level for studies being level 4 .

Table 1 Oxford Centre for Evidence-based Medicine 2011 Levels of Evidence for interventions ${ }^{33}$

Level 1 Systematic reviews

Level 2 Randomised controlled trials with low/moderate risk of bias or observational studies with dramatic effect

Level 3 Non-randomised controlled trials with low/moderate risk of bias or randomised controlled trials at high risk of bias

Level 4 Case series, case-control studies, historically controlled studies or non-randomised controlled trials at high risk of bias

Level 5 Mechanism-based reasoning/expert opinion 
We did not prospectively register the protocol for our systematic review. However, the full protocol is available by email, from the corresponding author (HP).

\section{RESULTS}

\section{Study selection}

A total of 1043 articles were identified during our searches. After removal of duplicates, 684 singular articles were found. After title and abstract selection seven articles ${ }^{34-40}$ were selected for full-text evaluation (figure 1). Two trials ${ }^{37} 39$ were excluded because we were unable to determine whether stem cells had actually been injected as no analyses were performed to investigate whether stem cells were actually present. One article was excluded ${ }^{40}$ because it was mostly in vitro and had no data of interest. One article ${ }^{38}$ because it concomitantly injected platelet-rich plasma and included patients with osteoarthritis. Three articles ${ }^{34-36}$ met the inclusion criteria. Hand searching revealed no additional articles. One additional article ${ }^{41}$ was identified by hand searching previously published reviews evaluating stem cell use in tendon disorders.

Four possibly unpublished studies ${ }^{42-45}$ were identified but after contacting the principal investigators, no data were made available. One unpublished trial ${ }^{42}$ was found to be published ${ }^{36}$ and had already been included in the results. Two unpublished trials ${ }^{43}$ were finalised at the time of writing the manuscript (June 2016). The final unpublished trial ${ }^{44}$ was mentioned to be recruiting, but this could not be verified with the author.

\section{Study characteristics}

The characteristics of the included studies are summarised in table 2. One matched non-randomised $\operatorname{study}^{35}$ and three case series were included for review. ${ }^{34} 3641$

A total of 79 patients were treated with two types of stem cells. The mean ages of the patients ranged from 24 to 61 years and the percentage of women ranged between $50 \%$ and $64 \%$. Two studies ${ }^{3435}$ evaluated the use of bone marrow-derived stem cells as an additive treatment for rotator cuff repair. One study $^{36}$ investigated the use of allogenic adipose-derived stem cells in lateral epicondylar tendinopathy. The last study ${ }^{41}$ investigated the use of bone marrow-derived stem cells in patellar tendinopathy.

Harvesting methods were homogenous across the bone marrow-derived trials with collection occurring from the anterior iliac crest. ${ }^{3435}{ }^{41}$ After harvesting, the bone marrow aspirate was concentrated using a variety of techniques and then injected in the patient. ${ }^{34} 35{ }^{41}$ None of these trials performed culturing or cell typing. One trial ${ }^{35}$ confirmed the presence of stem cells by counting the number of colony-forming fibroblasts in the samples. One trial ${ }^{34}$ counted the number of CD34 positive and mononuclear cells in its samples using flow cytometry. The last trial $^{41}$ used uncharacterised nucleated cells obtained from bone marrow aspirations.

The remaining study ${ }^{36}$ harvested allogenic adipose-derived stem cells from healthy donors' subcutaneous fat tissue. After aspiration, the lipoaspirate was purified and tested for viral, bacterial or fungal contamination. Culturing of the stromal vascular fraction was performed but the characterisation of stem cells was unclear. Before the cells were released for injection, a viable cell count was performed and purity of the cell line was assessed (80\% viable cells and $<1 \%$ CD45 positive cells as minimal criteria for release). Patients were injected locally using a double system syringe with fibrin clot to ensure local entrapment within a fibrin matrix.

\section{Risk of bias}

Three studies ${ }^{34} 3641$ were assessed using the Newcastle-Ottawa scale and one ${ }^{35}$ using the Cochrane Risk of bias tool. The motivation for the assessors' judgements can be found in online supplementary appendix 4.

The study by Hernigou et $a l^{35}$ was found to be at high risk of bias (figure 2). All domains were at high or unclear risk of bias.

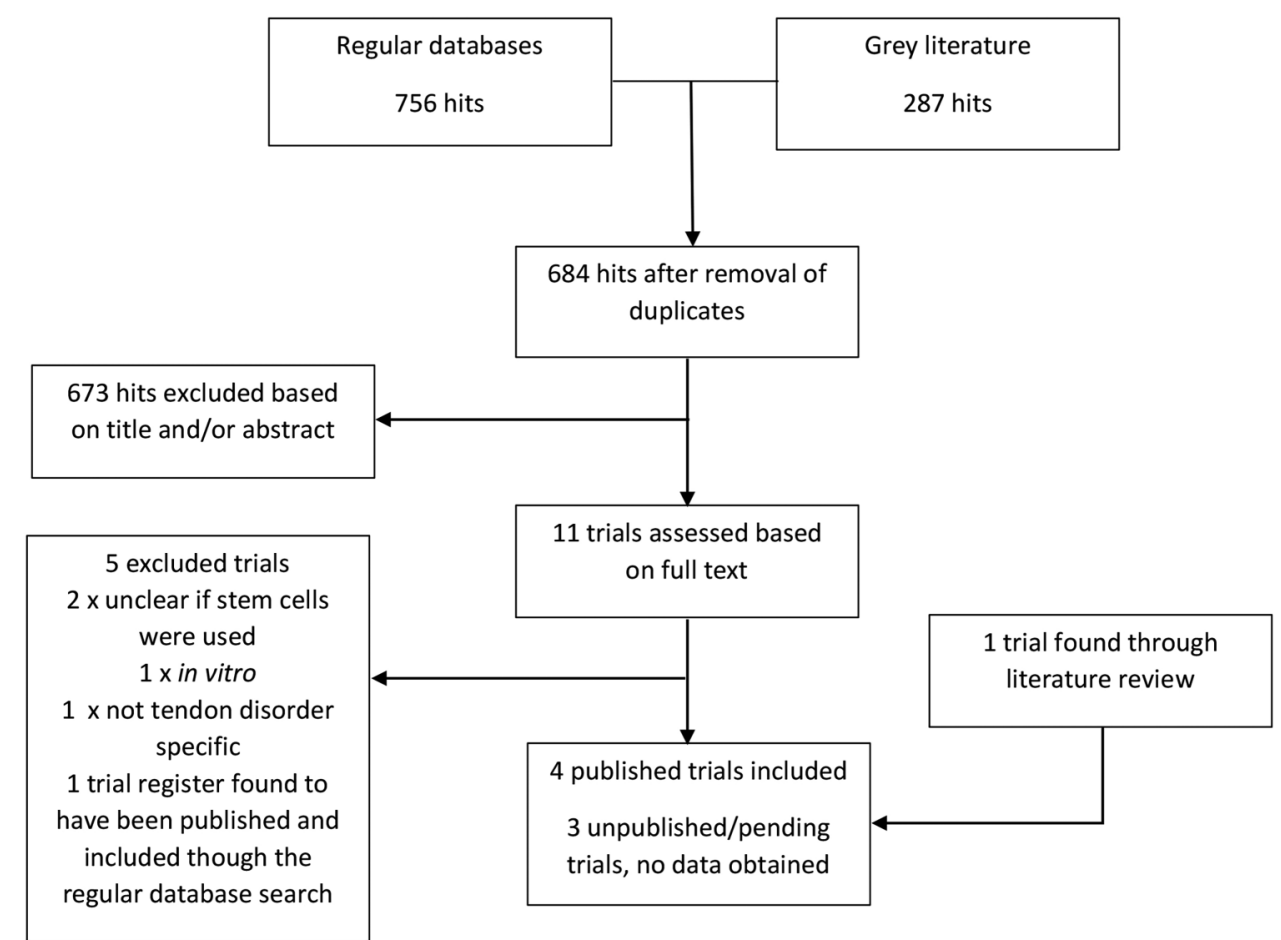

Figure 1 Selection process. 
Table 2 Study characteristics

\begin{tabular}{|c|c|c|c|c|c|c|c|c|c|c|c|}
\hline Author & Year & Study type & Lesion & n & $\begin{array}{l}\text { Per cent } \\
\text { of } \\
\text { females }\end{array}$ & $\begin{array}{l}\text { Mean age } \\
\text { (range) }\end{array}$ & $\begin{array}{l}\text { Last } \\
\text { follow-up }\end{array}$ & Stem cell type & Culturing & $\begin{array}{l}\text { Injection } \\
\text { frequency }\end{array}$ & $\begin{array}{l}\text { Mean number of } \\
\text { cells }\end{array}$ \\
\hline Lee et $a l^{36}$ & 2015 & Case series & $\begin{array}{l}\text { Lateral } \\
\text { epicondylar } \\
\text { tendinopathy }\end{array}$ & 12 & 58 & $51.8\left(9.5^{*}\right)$ & 52 weeks & $\begin{array}{l}\text { Allogenic } \\
\text { adipose-derived } \\
\text { stem cells }\end{array}$ & Yes & 1 & $10^{6}$ or $10^{7}$ \\
\hline $\begin{array}{l}\text { Pascual-Garrido } \\
\text { et }\left.a\right|^{41}\end{array}$ & 2012 & Case series & $\begin{array}{l}\text { Patellar } \\
\text { tendinopathy }\end{array}$ & 8 & 50 & $24(14-35)$ & 5 years & $\begin{array}{l}\text { Bone marrow } \\
\text { mononuclear cells }\end{array}$ & No & 1 & $45 \times 10^{3}$ \\
\hline Hernigou et $a \beta^{35}$ & 2014 & $\begin{array}{l}\text { Matched } \\
\text { non-randomised } \\
\text { trial }\end{array}$ & $\begin{array}{l}\text { Rotator cuff } \\
\text { tear }\end{array}$ & $\begin{array}{l}2 x \\
45\end{array}$ & 56 & 61 (49-71) & 10 years & $\begin{array}{l}\text { Bone } \\
\text { marrow-derived } \\
\text { stem cells }\end{array}$ & No & 1 & $51 \times 10^{3} \pm 25 \times 10^{3}$ \\
\hline $\begin{array}{l}\text { Ellera Gomez } \\
\text { et }\left.a\right|^{34}\end{array}$ & 2012 & Case series & $\begin{array}{l}\text { Rotator cuff } \\
\text { tear }\end{array}$ & 14 & 64 & 59.2 & 12 months & $\begin{array}{l}\text { Bone marrow } \\
\text { mononuclear cells }\end{array}$ & No & 1 & $\begin{array}{l}5.65 \times 10^{6}(\mathrm{CD} 34+, \\
\text { med) } \\
3.81 \times 10^{8} \\
\text { (mononuclear, } \\
\text { med) }\end{array}$ \\
\hline
\end{tabular}

*SD.

med, median; n, number of patients in the study.

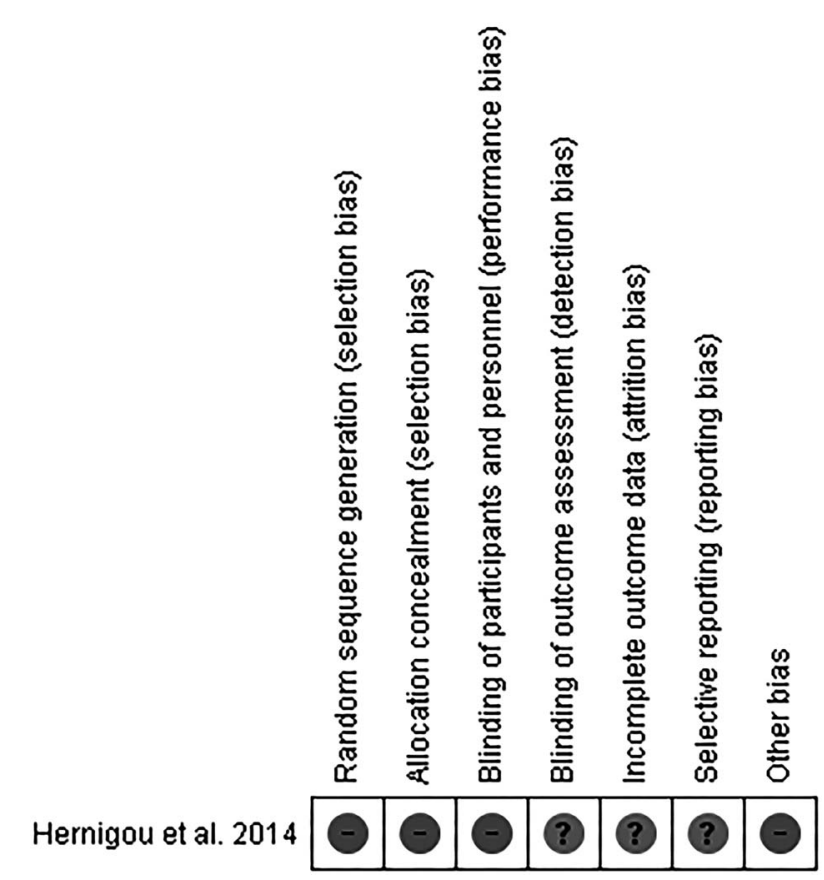

Figure 2 Risk of bias assessment using Cochrane risk of bias tool.

Owing to this high risk of bias the study was downgraded to level 4 evidence.

The number of stars awarded for case series ranged between two and four (figure 3). No quality subdivision was made. All studies lacked blinded outcome assessment and were unclear about the recruitment procedure.

\section{Tendon disorder types and outcomes}

Lateral epicondylar tendinopathy

One study ${ }^{36}$ investigated the use of allogenic adipose-derived stem cells in 12 patients with lateral epicondylar tendinopathy. There were statistically significant positive results compared with baseline at all time points $(6,12,26$ and 52 weeks postinjection) for Visual Analogue Scale (VAS) scores $(\mathrm{p}<0.001)$, Mayo Elbow Performance Index (MEPI) $(p<0.001)$ and ultrasound evaluation $(\mathrm{p}<0.001$ for longitudinal and transverse axes) (table 3).
Patellar tendinopathy

One study ${ }^{41}$ reported the use of bone marrow-derived stem cells in eight cases of patellar tendinopathy. There were statistically significant improvements after an average 5-year (range 3-6) period for Tegner Activity Scale score (2-8, p=0.006), International Knee Documentation Committee (IKDC) (36-69, $\mathrm{p}=0.047)$ and for Knee injury and Osteo arthritis Outcome Score (KOOS) subdomains symptoms $(44-71, \mathrm{p}=0.0086)$, activities in daily living $(63-90, p=0.0086)$ and sports $(24-63$, $\mathrm{p}=0.0078$ ) (table 3). No statistical improvement were observed for Lysholm score $(33-53, p=0.1043)$, KOOS pain $(47-63$, $\mathrm{p}=0.2399)$, KOOS quality of life $(50-71, \mathrm{p}=0.0825)$ and SF-12 mental and physical domains $(\mathrm{p}=0.5589$ and $\mathrm{p}=0.438$, respectively). On ultrasound evaluation, trends towards improvement were seen but these were not statistically evaluated.

Rotator cuff repair

Bone marrow-derived stem cells were injected at the tendonbone junction of arthroscopic rotator cuff repairs in two studies. $^{34} 35$ Combined, these two studies ${ }^{34} 35$ evaluated the results of 59 patients with stem cell injections. Both studies reported a reduced number of reruptures over time (table 3) compared either with historically selected controls ${ }^{35}$ (6 vs 25 in favour of stem cell injection, $\mathrm{p}<0.005$ ) or compared with the literature. $^{34}$ One study ${ }^{34}$ reported improvement of mean University of California at Los Angeles shoulder rating scale scores (12 SD 3.0 preoperative vs 31 SD 3.2, 12 months postoperative), but no statistical analysis was performed. The latter study $^{35}$ did not report any functional or other outcomes besides reruptures. Stem cell-treated patients with and without reruptures were compared and a dose-response analysis found significantly less bone marrow mononuclear cells per cubic centimetre $(1500+1200$ vs $4200+1900, \mathrm{p}<0.01)$ and less progenitor cells $(14000+9000$ vs $54000+23000, \mathrm{p}<0.01)$ in the grafts of patients with a rerupture.

\section{Adverse events}

Adverse events were reported in one trial. ${ }^{36}$ No serious adverse events were reported. Mild swelling was seen in 50\% of the participants within 48 hours postinjection which spontaneously subsided within 2 weeks. Two participants had ultrasonic evidence of joint effusion after 2 weeks. One case of delayed joint pain (7 weeks postinjection) was reported, which subsided with 
Figure 3 Risk of bias assessment using Newcastle-Ottawa scale for cohort studies.

\begin{tabular}{|c|c|c|c|}
\hline \multirow{2}{*}{\multicolumn{4}{|c|}{1 Recruitment procedure }} \\
\hline & & & \\
\hline 2 Inclusion criteria & 25 & & 25 \\
\hline 3 Ascertainment of exposure & 25 & & 2 \\
\hline \multicolumn{4}{|l|}{4 Blinded outcome assessment } \\
\hline 5 Follow-up adequacy & $2 \sqrt{2}$ & $\frac{2}{2}$ & \\
\hline 6 Intention-to-treat analysis & 2 & 25 & \\
\hline
\end{tabular}

Table 3 Study outcomes

\begin{tabular}{|c|c|c|c|c|c|}
\hline Author & Year & Main outcomes & Significance & $\begin{array}{l}\text { Level of } \\
\text { evidence }\end{array}$ & Adverse events \\
\hline Lee et $a l^{36}$ & 2015 & $\begin{array}{l}\text { VAS }(0-100) \text { at } 6,12 \text {, } \\
24 \text { and } 52 \text { weeks } \\
\text { Modified mayo elbow } \\
\text { performance index } \\
\text { (MEPI) } \\
\text { Largest defect area of } \\
\text { common extensor } \\
\text { origin tendon }\end{array}$ & $p<0.001$ & 4 & $\begin{array}{l}6 \text { cases of mild swelling with spontaneous } \\
\text { resolution within } 2 \text { weeks, } \\
2 \text { cases of joint effusion after } 1 \text { month, resolved } \\
\text { within } 1 \text { months, not significant. } 1 \text { case of } \\
\text { delayed elbow pain treated with tramadol and } \\
\text { acetaminophen }\end{array}$ \\
\hline $\begin{array}{l}\text { Pascual-Garrido } \\
\text { et }\left.a\right|^{41}\end{array}$ & 2012 & $\begin{array}{l}\text { Tegner } \\
\text { Lysholm } \\
\text { IKDC } \\
\text { KOOS } \\
\text { Pain } \\
\text { Symptoms } \\
\text { ADL } \\
\text { Sport } \\
\text { QOL } \\
\text { SF-12 } \\
\text { Mental } \\
\text { Physical } \\
\text { Ultrasound evaluation }\end{array}$ & $\begin{array}{l}p=0.0061 \\
p=0.1043 \\
p=0.047 \\
p=0.2399 \\
p=0.0086 \\
p=0.0246 \\
p=0.0078 \\
p=0.0825 \\
p=0.5589 \\
p=0.438 \\
N A . \text { All patients had grade } 2-3 \text { before inoculation. } \\
6 / 9 \text { had grade } 1 \text { after } 6 \text { months, one patient had } \\
\text { grade } 3\end{array}$ & 4 & Not reported \\
\hline Hernigou et $a l^{35}$ & 2014 & $\begin{array}{l}\text { MRI assessment of cuff } \\
\text { healing: } \\
\text { Retears confirmed by } \\
\text { MRI after } 10 \text { years } \\
\text { Intervention: } \\
\text { No change of MRI } \\
\text { healing grade after } \\
10 \text { years: } \\
\text { Mean cells success } \\
\text { versus no success } \\
\text { (retear): } \\
\text { Bone marrow } \\
\text { mononuclear cells } \\
\text { Progenitor cells } \\
\text { Non-healing in the first } \\
6 \text { months: }\end{array}$ & $\begin{array}{l}p<0.01 \\
\text { Success: } 4200 \pm 1900 / \mathrm{cm}^{3} \text { vs no success: } \\
1500 \pm 1200 / \mathrm{cm}^{3} \\
p<0.01 \\
\text { Success: } 54000+23000 / \mathrm{cm}^{3} \text { vs no success: } \\
14000 \pm 9000 / \mathrm{cm}^{3} \\
\text { NA } 0 / 45 \text { intervention vs } 8 / 45 \text { control }\end{array}$ & 4 & Not reported \\
\hline $\begin{array}{l}\text { Ellera Gomez } \\
\text { et } a l^{34}\end{array}$ & 2012 & $\begin{array}{l}\text { UCLA score } \\
\text { MRI analysis }\end{array}$ & $\begin{array}{l}\text { NA, increase from } 12 \text { to } 31 \\
\text { NA, } 14 \text { cases of full tendon integrity, } 8 / 14 \text { low } \\
\text { signal intensity along supraspinatus, } 11 / 14 \text { high } \\
\text { signal artefact at the bursal and tendon, } 6 / 14 \text { high } \\
\text { signal intensity zone at the critical zone }\end{array}$ & 4 & Not reported \\
\hline
\end{tabular}

IKDC, International knee documentation committee; KOOS, Knee Injury and Osteoarthritis Outcome Score; NA, not available or applicable; SF-12, short form health survey 12; UCLA score, University of California at Los Angeles Shoulder rating scale; VAS, visual analogue scale.

rest and analgesics. No immunologic reactions were found based on $\mathrm{CD}^{+}$and $\mathrm{CD} 8^{+} \mathrm{T}$ cell ratio.

\section{Summary}

Four trials at high risk of bias (level 4 of evidence) were identified during this review. One case series ${ }^{36}$ evaluated adipose- derived stem cells in lateral epicondylar tendinopathy and found improvements in VAS, MEPI and ultrasound evaluations, when compared with baseline. One case series ${ }^{41}$ was available evaluating bone marrow-derived stem cells in patellar tendinopathy. It found improved Tegner, IKDC and KOOS subdomains compared with baseline but failed to find improvements in Lysholm, 
SF-12 and other KOOS subdomains. One case series ${ }^{34}$ and one non- $\mathrm{RCT}^{35}$ were found evaluating bone marrow-derived stem cells in rotator cuff repair surgery. Historical controls were used in one trial ${ }^{35}$ and reported a reduced retear rate. The other trial $^{34}$ reported lower retear rates compared with the literature and improved UCLA scores compared with baseline. One trial ${ }^{36}$ reported adverse events. None of these adverse events were of grave nature.

\section{DISCUSSION}

We performed a systematic review to evaluate the body of evidence for the use of stem cells in tendon disorders. A total of four trials were found, ${ }^{34-36}{ }^{41}$ only one ${ }^{35}$ of which used a control group. Three unpublished trials $^{43-45}$ were identified, two ${ }^{43} 45$ of which have been finalised. The use of stem cells was tested in patellar tendinopathy, lateral epicondylar tendinopathy and rotator cuff tears. Bone marrow-derived and allogenic adipose-derived stem cells were used. All trials were rated as level 4 evidence, making only level 4 evidence available for the efficacy of stem cell use in tendon disorders.

In lateral epicondylar tendinopathy, patellar tendinopathy and rotator cuff repairs improved healing evaluated through imaging modalities such as MRI or ultrasound, functional outcomes and pain scores were found compared with baseline. Reruptures of repaired rotator cuffs treated with stem cell injections peroperatively, were reduced when compared with the literature or historically selected controls. Safety was poorly reported as only one trial ${ }^{36}$ reported adverse events but found them to be generally of mild nature such as transient pain, swelling or effusion.

\section{Risk of bias in the identified trials}

All trials were at high risk of bias and had major methodological limitations. First, only one trial included a control group ${ }^{35}$ though it should be noted that this was a historically controlled study, consequently, no randomisation could be performed. Neither patients, personnel or outcome assessors were blinded to group allocation. This allowed for a high risk of selection, performance and detection bias. All other trials ${ }^{34} 36{ }^{41}$ lacked a control group, allowing for alternative explanations of their positive results (eg, natural course, confounding, placebo). Lateral epicondylar tendinopathy, for example, is a benign condition, usually resolving within $12-18$ months. ${ }^{9}{ }^{46}$ It is possible that the ultrasound findings in the trial by Lee $e t a l^{36}$ are a result of natural healing. Ellera Gomez $e a^{34}$ compared the low retear rates with the literature, however, rerupture rates vary greatly between studies. ${ }^{47}{ }^{48}$ Given the small number of patients in this study, and a $0 \%$ rerupture rate within 12 months, this may still lie within the normal distribution of probability.

The placebo effect might account for the positive results of Pascual-Garrido et al..$^{41}$ The inclusion of non-adult participants (ie, $<18$ years) in this trial ${ }^{41}$ may also limit the generalisability of the study's findings to the adult population. We question the ethical soundness of highly experimental stem cell therapy in minors. Also, a high risk of selection and attrition bias seems to be present in this study; only patients who were able to complete the 2-year follow-up were included in the report.

Overall, due to high risk of bias across studies, all trials were assessed as level 4 evidence. Therefore, these results should be interpreted with great caution.

Stem cells have been used in medicine in attempts to treat a variety of conditions. ${ }^{49-54}$ Their use in tendinopathy is relatively new and this review critically examined the body of evidence in humans. It is now clear that the evidence to date is very poor with only highly biased trials reporting on the efficacy of stem cell treatment. Previous reviews ${ }^{14-16}$ which included veterinary studies, have reported more trends towards efficacy but, as is the case with this review, all concluded that there is almost no evidence for stem cell therapy in the treatment of tendon disorders in humans. Three ongoing trials ${ }^{43-45}$ were found and we hope to review their results once they are published. Despite the fact that these trials may influence our results, we felt it was necessary to publish this result now considering the growing interest in this subject and the growing number of stem cell clinics. ${ }^{29}$

\section{Theoretical rationale for the use of stem cells to treat tendon disorders}

Mesenchymal stem cells (MSCs) are defined as self-renewing and multipotent cells capable of differentiating into multiple cell types, including osteocytes, chondrocytes, adipocytes, hepatocytes, myocytes and cardiomyocytes. ${ }^{55}$ MSCs were originally isolated from the bone marrow stroma but have also been identified also in other tissues, such as fat, epidermis and umbilical cord blood. ${ }^{56} 57$ The International Society for Cellular Therapy released a position statement in $2006^{58}$ outlining the minimal criteria for defining MSCs: adherence to plastic, the presence of CD73, CD90 and CD105 antigen markers, absence of CD11b, CD14, CD19, CD34, CD45, CD79 $\alpha$ and HLA class II and the ability to differentiate in vitro.

The mechanisms by which stem cells are proposed to repair injured tendons can be considered twofold. First, stem cells are proposed to differentiate into tenocytes and restart the healing process by differentiating into tenocytes. ${ }^{18}{ }^{59}{ }^{60}$ However, the fate of stem cells after injection is not well studied in tendon injury and research suggests that few cells remain in situ after implantation. ${ }^{14-16} 25$ 61 Therefore, it is questionable whether there are enough cells to be of value for tendon repair. Second, the paracrine effect of stem cells is hypothesised to be beneficial for tissue repair. ${ }^{14} 6263$ Several reviews ${ }^{25}{ }^{63-67}$ have summarised the number of growth factors and cytokines that are secreted by MSCs and how these factors influence, often in animal models, the repair mechanisms of injured tendons. It should be noted that other injection therapies with growth factors, such as platelet-rich plasma, have mostly failed to demonstrate their efficacy within tendon disorder treatment. ${ }^{11} 1268$

\section{Safety and quality of stem cell preparations}

The MSCs used in the reviewed trials have not been found to be associated with malignancy. ${ }^{69}{ }^{70}$ However, safety concerns remain an important issue for clinicians. ${ }^{62}$ Of the included trials, only one ${ }^{36}$ reported adverse events, finding only mild adverse events within a 1-year follow-up. The remaining trials $^{34} 35{ }^{41}$ failed to report adverse events allowing for potentially dangerous side effects to have gone unnoticed.

Although all trials ${ }^{34-36} 41$ documented the mean number of injected stem cells, the ways of analysing the numbers and cell types varied across the studies. As mentioned earlier, specific criteria are available. ${ }^{58}$ Of the included studies, only one trial ${ }^{36}$ partially fulfilled these criteria. Ellera Gomes et al ${ }^{34}$ used CD34 and mononuclear cell analysis, which is more specific for haematopoietic progenitor cells rather than bone marrow MSCs. ${ }^{55} 58$ The use of colony-forming unit counting by Hernigou $e t a l^{35}$ is a method that seems incomplete without surface marker analysis. ${ }^{71}$ Considering the above, the methods used by Pascual-Garrido et $a l^{41}$ also seem inadequate to properly confirm adequate stem cell numbers.

In three studies, ${ }^{34} 35$ stem cells concentrates were used and culturing was never performed. The mean number of injected cells varied widely with up to a factor of 1000 in difference 
generally favouring culturing. Two studies ${ }^{35} 36$ analysed whether dosage played a role in the healing process. Lee $e a l^{36}$ found no differences between $10^{6}$ or $10^{7}$ cells, Hernigou et al ${ }^{35}$ found significantly lower number of stem cells and progenitor cells in patients with graft failures. The other two studies ${ }^{34} 41$ did not perform dosage analyses.

One concern with uncultured stem cell concentrates as used in the identified trials ${ }^{34} 35{ }^{41}$ is the presence of multiple cell types. ${ }^{62}$ As to date there is no consensus ${ }^{62}{ }^{72}$ regarding whether this non-cultured concentrating method is equally effective as the use of cultured stem cell implantation or injection, we cannot judge whether this is an important factor influencing the outcomes. Furthermore, we could not evaluate whether cell dose may play a role in possible therapeutic efficacy due to the heterogeneity in cell numbers, types of tendon disorders and the low number of participants.

\section{Limitations}

We excluded two trials ${ }^{37} 39$ that used bone marrow aspirates, and we discovered two other trials ${ }^{73}$ that made attempts to investigate stem cell efficacy in tendon disorders. All these trials were excluded because no analysis was performed to confirm the presence of potential stem cells in the intervention. We therefore believe their exclusion is justified, as inclusion would have created even more heterogeneity in this review. Furthermore, publication bias could not be investigated due to the small number of trials. This might mean that overly positive results are presented in our review. However, we aimed to control for publication bias as much as possible. We searched several grey literature databases and multiple trial registers to find all relevant existing studies investigating stem cell therapy in tendon disorders. Even though no protocol for this review was registered, we wrote and followed an a priori protocol which is freely available through the corresponding author (HP). Despite these limitations, we believe that this review provides the clinician with a good overview of the current evidence for using stem cells to treat of tendon disorders.

\section{Future directions}

As illustrated by this review, we are currently still a long way from being able to endorse, based on high-quality evidence, the addition of stem cells to the arsenal of possible treatments for tendon disorders. Many gaps in our knowledge about the efficacy, safety, administration route, timing of administration, dosage and consideration of mechanical stimulation ${ }^{13} 6075$ are evident when reviewing the available literature. Future research has many questions to answer but more importantly, we believe that sound scientific investigations should be performed. As we illustrated with our risk of bias assessment, the current evidence is tainted with methodological flaws that allow for high risks of biased results. In the future, stem cell therapies should be tested RCTs, with appropriate characterisation of the cells, proper randomisation procedures and allocation concealment. Considering the results of currently available treatments like eccentric exercises, ${ }^{5}{ }^{6}$ we believe it to be important to compare the possible efficacy of stem cell treatments with these currently accepted treatment modalities. Furthermore, studies should incorporate blinding of participants, personnel and outcome assessors. Adverse events should be recorded and reported in all cases. Finally, sample sizes should be large enough to find clinically relevant differences.

The above discussed shortcomings and concerns are in congruence with the findings of the recently published position statement of the Australasian College of Sports Physicians. ${ }^{62}$ On the efficacy of stem cell treatment for tendinopathy they stated that there is a lack of evidence, which is a statement we believe to still hold true despite the availability of human trials. Furthermore, the concerns about long-term safety and poor research is one we share alike.

\section{CONCLUSION}

There is no evidence to support the use of stem cell therapy in tendon disorders. Overall, only level 4 evidence was found for the effectiveness of stem cells, and this is insufficient to recommend the use of stem cells of any kind in the treatment of any kind of tendon disorder. All studies are at high risk of bias and results must be replicated through good practice research before more general clinical implementation can be recommended.

\section{What are the findings?}

- The current level of evidence for stem cell use in tendon disorders is extremely poor.

- Only case reports or poorly designed trials are available.

- The results from the identified trials are at high risk of bias.

\section{How might it impact on clinical practice in the future?}

- The use of stem cell therapy for tendon disorders in clinical practice is not suitable outside of an appropriate ethics approved clinical trial.

- Patients seeking stem cell treatment for their tendon disorders can now be made aware of the lack of evidence and potential dangers.

- In cases where stem cells are used, safety must be monitored and reported by the investigator.

Acknowledgements The authors would like to thank Roos Steenhuis, research librarian, Onze Lieve Vrouwe Gasthuis West, Amsterdam, for her work in formulating their search.

Funding The Dutch National Olympic Committee.

Disclaimer The Dutch National Olympic Committee had no influence in the performance or publication of this review.

Competing interests HP and MW received a grant from the Dutch National Olympic Committee for the realisation of this review. HP reports receiving grants from the Dutch National Olympic Committee and the Sports Physician group, Department of Sports Medicine, OLVG West, Amsterdam, outside the submitted work.

Provenance and peer review Not commissioned; externally peer reviewed.

\section{REFERENCES}

1 Albers IS, Zwerver J, Diercks RL, et al. Incidence and prevalence of lower extremity tendinopathy in a Dutch general practice population: a cross sectional study. BMC Musculoskelet Disord 2016;17:16.

2 Ackermann PW, Renström P. Tendinopathy in sport. Sports Health 2012;4: 193-201.

3 Maffulli N, Wong J, Almekinders LC. Types and epidemiology of tendinopathy. Clin Sports Med 2003;22:675-92.

4 Maffulli N, Khan KM, Puddu G. Overuse tendon conditions: time to change a confusing terminology. Arthroscopy 1998;14:840-3.

5 Murtaugh B, Ihm JM. Eccentric training for the treatment of tendinopathies. Curr Sports Med Rep 2013;12:175-82.

6 Andres BM, Murrell GA. Treatment of tendinopathy: what works, what does not, and what is on the horizon. Clin Orthop Relat Res 2008;466:1539-54. 
7 Leal C, Ramon S, Furia J, et al. Current concepts of shockwave therapy in chronic patellar tendinopathy. Int I Surg 2015;24(Pt B):160-4.

8 van der Worp H, van den Akker-Scheek I, van Schie H, et al. ESWT for tendinopathy: technology and clinical implications. Knee Surg Sports Traumatol Arthrosc 2013;21:1451-8

9 Sims SE, Miller K, Elfar JC, et al. Non-surgical treatment of lateral epicondylitis: a systematic review of randomized controlled trials. Hand (N Y) 2014;9:419-46.

10 Coombes BK, Bisset L, Vicenzino B. Efficacy and safety of corticosteroid injections and other injections for management of tendinopathy: a systematic review of randomised controlled trials. Lancet 2010;376:1751-67.

11 Tsikopoulos K, Tsikopoulos I, Simeonidis E, et al. The clinical impact of platelet-rich plasma on tendinopathy compared to placebo or dry needling injections: A meta-analysis. Phys Ther Sport 2016;17:87-94.

12 de Vos RJ, Windt J, Weir A. Strong evidence against platelet-rich plasma injections for chronic lateral epicondylar tendinopathy: a systematic review. $\mathrm{Br}$ J Sports Med 2014;48:952-6.

13 Lu YF, Chan KM, Li G, et al. Tenogenic differentiation of mesenchymal stem cells and noncoding RNA: From bench to bedside. Exp Cell Res 2016;341:237-42.

14 Lui PP. Stem cell technology for tendon regeneration: current status, challenges, and future research directions. Stem Cells Cloning 2015;7:163-74.

15 Lui PP, Ng SW. Cell therapy for the treatment of tendinopathy-a systematic review on the pre-clinical and clinical evidence. Semin Arthritis Rheum 2013;42:651-66.

16 Obaid H, Connell D. Cell therapy in tendon disorders: what is the current evidence? Am J Sports Med 2010;38:2123-32.

17 Valencia Mora M, Ruiz Ibán MA, Díaz Heredia J, et al. Stem cell therapy in the management of shoulder rotator cuff disorders. World I Stem Cells 2015;7:691-9

18 Ruzzini L, Longo UG, Rizzello G, et al. Stem cells and tendinopathy: state of the art from the basic science to clinic application. Muscles Ligaments Tendons J 2012:2:235-8

$19 \mathrm{Xu}$ Y, Murrell GA. The basic science of tendinopathy. Clin Orthop Relat Res 2008:466:1528-38

20 Cook JL, Purdam CR. Is tendon pathology a continuum? A pathology model to explain the clinical presentation of load-induced tendinopathy. $\mathrm{Br} / \mathrm{Sports} \mathrm{Med}$ 2009;43:409-16.

21 Lui PP. Histopathological changes in tendinopathy — potential roles of BMPs? Rheumatology (Oxford) 2013;52:2116-26.

22 Rees JD, Stride M, Scott A. Tendons-time to revisit inflammation. Br I Sports Med 2014:48:1553-7

23 Battery L, Maffulli N. Inflammation in overuse tendon injuries. Sports Med Arthrosc 2011;19:213-17.

24 Fredberg U, Stengaard-Pedersen K. Chronic tendinopathy tissue pathology, pain mechanisms, and etiology with a special focus on inflammation. Scand J Med Sci Sports 2008:18:3-15.

25 Nixon AJ, Watts AE, Schnabel LV. Cell- and gene-based approaches to tendon regeneration. J Shoulder Elbow Surg 2012;21:278-94.

26 Guevara-Alvarez A, Schmitt A, Russell RP, et al. Growth factor delivery vehicles for tendon injuries: Mesenchymal stem cells and Platelet Rich Plasma. Muscles Ligaments Tendons J 2014;4:378-85.

27 Caplan Al, Dennis JE. Mesenchymal stem cells as trophic mediators. J Cell Biochem 2006;98:1076-84.

28 Pers YM, Ruiz M, Noël D, et al. Mesenchymal stem cells for the management of inflammation in osteoarthritis: state of the art and perspectives. Osteoarthritis Cartilage 2015;23:2027-35.

29 Turner L, Knoepfler P. Selling Stem Cells in the USA: Assessing the Direct-to-Consumer Industry. Cell Stem Cell 2016;19:154-7.

30 Higgins JPT, Green S (editors). Cochrane Handbook for Systematic Reviews of Interventions Version 5.1.0 [updated March 2011]. The Cochrane Collaboration, 2011. Available from www.handbook.cochrane.org.

31 Winters $\mathrm{M}$, Eskes $\mathrm{M}$, Weir $\mathrm{A}$, et al. Treatment of medial tibial stress syndrome: a systematic review. Sports Med 2013;43:1315-33.

32 Wells GA, Shea B, O'Connell D, et al. The Newcastle-Ottawa Scale (NOS) for assessing the quality of nonrandomised studies in meta-analyses. http://www.ohri. ca/programs/clinical_epidemiology/oxford.asp (accessed 22 Apr 2016).

33 Group OLoEW. The Oxford Levels of Evidence 2. 2011. http://www.cebm.net/ ocebm-levels-of-evidence/ (accessed 22 Apr 2016).

34 Ellera Gomes JL, da Silva RC, Silla LM, et al. Conventional rotator cuff repair complemented by the aid of mononuclear autologous stem cells. Knee Surg Sports Traumatol Arthrosc 2012;20:373-7.

35 Hernigou P, Flouzat Lachaniette $\mathrm{CH}$, Delambre J, et al. Biologic augmentation of rotator cuff repair with mesenchymal stem cells during arthroscopy improves healing and prevents further tears: a case-controlled study. Int Orthop 2014;38:1811-18.

36 Lee SY, Kim W, Lim C, et al. Treatment of Lateral Epicondylosis by Using Allogeneic Adipose-Derived Mesenchymal Stem Cells: A Pilot Study. Stem Cells 2015:33:2995-3005.

37 Moon $\mathrm{YL}$, Jo SH, Song $\mathrm{CH}$, et al. Autologous bone marrow plasma injection after arthroscopic debridement for elbow tendinosis. Ann Acad Med Singapore 2008;37:559-63.
38 Centeno CJ, Al-Sayegh H, Bashir J, et al. A prospective multi-site registry study of a specific protocol of autologous bone marrow concentrate for the treatment of shoulder rotator cuff tears and osteoarthritis. J Pain Res 2015;8:269-76

39 Stein BE, Stroh DA, Schon LC. Outcomes of acute Achilles tendon rupture repair with bone marrow aspirate concentrate augmentation. Int Orthop 2015;39:901-5.

40 Broese M, Toma I, Haasper C, et al. Seeding a human tendon matrix with bone marrow aspirates compared to previously isolated hBMSCs —an in vitro study. Technol Health Care 2011;19:469-79.

41 Pascual-Garrido C, Rolón A, Makino A. Treatment of chronic patellar tendinopathy with autologous bone marrow stem cells: a 5-year-followup. Stem Cells Int 2012:2012:953510.

42 Chung SC. Treatment of Tendon Injury Using Mesenchymal Stem Cells (ALLO-ASC), NCT01856140. https://clinicaltrials.gov/show/NCT01856140

43 Chung SG. Treatment of Tendon Injury Using Allogenic Adipose-derived Mesenchymal Stem Cells (Rotator Cuff Tear), NCT02298023. https://clinicaltrials. gov/show/NCT02298023

44 Goldberg A. Autologous Stem Cells in Achilles Tendinopathy (ASCAT) NCT02064062. https://clinicaltrials.gov/show/NCT02064062

45 Gutierrez BF. Mensenchymal Stem Cell (MSC) Included in OrthADAPT Membrane for Rotator Cuff Tears Repair (msctendonrep), NCT01687777. https://clinicaltrials.gov/ show/NCT01687777

46 Ahmad Z, Siddiqui N, Malik SS, et al. Lateral epicondylitis: a review of pathology and management. Bone Joint J 2013;95-B:1158-64.

47 Slabaugh MA, Nho SJ, Grumet RC, et al. Does the literature confirm superior clinical results in radiographically healed rotator cuffs after rotator cuff repair? Arthroscopy 2010;26:393-403.

48 Randelli P, Spennacchio P, Ragone V, et al. Complications associated with arthroscopic rotator cuff repair: a literature review. Musculoskelet Surg 2012;96:9-16.

49 Compagna R, Amato B, Massa S, et al. Cell Therapy in Patients with Critical Limb Ischemia. Stem Cells Int 2015:2015:931420.

50 Filardo G, Perdisa F, Roffi A, et al. Stem cells in articular cartilage regeneration. J Orthop Surg Res 2016;11:42.

51 Fisher SA, Zhang $\mathrm{H}$, Doree $\mathrm{C}$, et al. Stem cell treatment for acute myocardial infarction. Cochrane Database Syst Rev 2015;(9):CD006536.

52 Kułak-Bejda A, Kułak P, Bejda G, et al. Stem cells therapy in cerebral palsy: A systematic review. Brain Dev 2016;38:699-705.

53 Peruzzi M, De Falco E, Abbate A, et al. State of the Art on the Evidence Base in Cardiac Regenerative Therapy: Overview of 41 Systematic Reviews. Biomed Res Int 2015;2015:613782.

54 Wormald JC, Fishman JM, Juniat $\mathrm{S}$, et al. Regenerative medicine in otorhinolaryngology. J Laryngol Otol 2015;129:732-9.

55 Kolf CM, Cho E, Tuan RS. Mesenchymal stromal cells. Biology of adult mesenchymal stem cells: regulation of niche, self-renewal and differentiation. Arthritis Res Ther 2007;9:204.

56 Phinney DG, Prockop DJ. Concise review: mesenchymal stem/multipotent stromal cells: the state of transdifferentiation and modes of tissue repair-current views. Stem Cells 2007;25:2896-902.

57 Gnecchi M, Melo LG. Bone marrow-derived mesenchymal stem cells: isolation, expansion, characterization, viral transduction, and production of conditioned medium. Methods Mol Biol 2009:482:281-94.

58 Dominici M, Le Blanc K, Mueller I, et al. Minimal criteria for defining multipotent mesenchymal stromal cells. The International Society for Cellular Therapy position statement. Cytotherapy 2006;8:315-17.

59 Mautner K, Blazuk J. Where do injectable stem cell treatments apply in treatment of muscle, tendon, and ligament injuries? PM R 2015;7(4 Suppl):S33-40.

60 Gaspar D, Spanoudes K, Holladay C, et al. Progress in cell-based therapies for tendon repair. Adv Drug Deliv Rev 2015;84:240-56.

61 Guest DJ, Smith MR, Allen WR. Monitoring the fate of autologous and allogeneic mesenchymal progenitor cells injected into the superficial digital flexor tendon of horses: preliminary study. Equine Vet J 2008;40:178-81.

62 Osborne H, Anderson L, Burt P, et al. Australasian College of Sports Physicians-position statement: the place of mesenchymal stem/stromal cell therapies in sport and exercise medicine. Br J Sports Med 2016;50:1237-44.

63 Ahmad Z, Henson F, Wardale J, et al. Review article: Regenerative techniques for repair of rotator cuff tears. J Orthop Surg (Hong Kong) 2013;21:226-31.

64 Liu H, Zhu S, Zhang C, et al. Crucial transcription factors in tendon development and differentiation: their potential for tendon regeneration. Cell Tissue Res 2014;356:287-98.

65 Branford OA, Klass BR, Grobbelaar AO, et al. The growth factors involved in flexor tendon repair and adhesion formation. I Hand Surg Eur Vol 2014:39:60-70.

66 Bedi A, Maak T, Walsh C, et al. Cytokines in rotator cuff degeneration and repair J Shoulder Elbow Surg 2012;21:218-27.

67 Meirelles Lda S, Fontes AM, Covas DT, et al. Mechanisms involved in the therapeutic properties of mesenchymal stem cells. Cytokine Growth Factor Rev 2009;20:419-27. 
68 de Vos RJ, van Veldhoven PL, Moen MH, et al. Autologous growth factor injections in chronic tendinopathy: a systematic review. Br Med Bull 2010;95:63-77.

69 Casiraghi F, Remuzzi G, Abbate M, et al. Multipotent mesenchymal stromal cell therapy and risk of malignancies. Stem Cell Rev 2013;9:65-79.

70 Lalu MM, Mclntyre L, Pugliese C, et al. Safety of cell therapy with mesenchymal stromal cells (SafeCell): a systematic review and meta-analysis of clinical trials. PLOS ONE 2012;7:e47559.

71 Sensebé L, Bourin P, Tarte K. Good manufacturing practices production of mesenchymal stem/stromal cells. Hum Gene Ther 2011;22:19-26.
72 Sampson S, Botto-van Bemden A, Aufiero D. Autologous bone marrow concentrate: review and application of a novel intra-articular orthobiologic for cartilage disease. Phys Sportsmed 2013;41:7-18.

73 Yoon JP, Chung SW, Kim JY, et al. Outcomes of Combined Bone Marrow Stimulation and Patch Augmentation for Massive Rotator Cuff Tears. Am J Sports Med 2016:44:963-71.

74 Singh A, Gangwar DS, Singh S. Bone marrow injection: A novel treatment for tennis elbow. J Nat Sci Biol Med 2014;5:389-91.

75 Chen JL, Zhang W, Liu ZY, et al. Physical regulation of stem cells differentiation into teno-lineage: current strategies and future direction. Cell Tissue Res 2015;360:195-207. 